\title{
On the Edge of Facts and Hypotheses
}

\author{
Martin H. Schöni \\ Medizinische Kinderklinik, Inselspital, Berne, Switzerland
}

Despite extensive and rigorous research, some diseases remain poorly understood. Such entities have been named idiopathic, common and variable, cryptogenic or of unknown origin. Most of the times authors who deal with cases of unknown origin or of obscure etiology summarize their reports with hypotheses or ask for further studies. This is also the case in the paper presented by Gerd-Christian Sutor and Helmut Fabel in this issue of Respiration [1].

They report on the fatal outcome of a 19-year-old female with an almost life-long history of a combined immunodeficiency with sarcoidosis. This is one of those cases in which the simultaneous occurrence of two extremely rare diseases suggests a common or eventually dependent etiology and where one rare fatal disease of childhood combines with another occasionally fatal one, which is also not so often recognized in children.

Sarcoidosis in childhood is rare with an incidence of approximately $20-180$ cases per 100,000 population, depending on ethnicity and geographical location. In about $60 \%$, pulmonary involvement resolves over time and only a few patients progress to lung fibrosis and severe pulmonary complications [2]. Also known as 'acquired hypogammaglobulinemia', 'late onset hypogammaglobulinemia', or 'adult onset hypogammaglobulinemia', common variable immunodeficiency (CVID) affects about 1-2 cases per 100,000, appears in $95 \%$ of the patients after the age of 6 years and is thought to be due to an arrested B-cell differentiation based on a defect in the HLA coding region on chromosome 6 . As a complication of CVID sev-

\begin{tabular}{ll}
\hline KARGER & ( 2000 S. Karger AG, Basel \\
0025-7931/00/0672-0135\$17.50/0 \\
$\begin{array}{l}\text { Fax +4161306 1234 } \\
\begin{array}{l}\text { E-Mail karger@karger.ch } \\
\text { www.karger.com }\end{array}\end{array}$ & $\begin{array}{l}\text { Accessible online at: } \\
\text { www.karger.com/journals/res }\end{array}$
\end{tabular}

eral associated diseases are described such as autoimmune disorders, particularly hemolytic anemia, thrombocytopenia, autoimmune neutropenia, lymphoid interstitial pneumonitis and the emergence of noncaseating granulomas of the lung, spleen, skin and liver [3]. The differential diagnosis of noncaseating granulomas is broad and the granulomas are not always diagnostic for sarcoidosis. They are associated with bacterial infections such as brucellosis, yersiniosis, tuberculosis and atypical mycobacterial diesease; with fungal infections such as histoplasmosis, coccidioidomycosis, blastomycosis and cryptococcosis, with spirochetal and protozoal disease such as tertiary syphilis, toxoplasmosis and leishmaniasis; with allergen exposure and extrinsic allergic alveolitis, and an extensive list of other diseases including Crohn's disease, primary biliary cirrhosis, granulomatous hepatitis, Whipple's and Wegener's granulomatosis, Churg-Strauss allergic granulomatosis, giant cell arteritis, polyarteritis, systemic lupus erythematosus, histiocytosis $\mathrm{X}$ and others. Most of these have been excluded by the authors; however, it remains unresolved whether this patient could have suffered from extensive and disseminated atpyical mycobacterial infection (MOTT, mycobacteria other than $\mathrm{Tbc}$ ), which has not been addressed in this report. Mycobacterial blood cultures and the use of PCR in respiratory tract and biopsy specimens may have increased the diagnostic sensitivity. Whether PCR-based tests to detect MOTT or Tbc have been performed is not clear.

Although unreliable in adults, serum ACE levels as well as hypercalcemia and hypercalciuria help to substan-

Prof. Dr. med. Martin H. Schön

Med. Kinderklinik, Kinderuniversitätsklinik

Inselspital

CH-3010 Bern

Tel. +4131632 94 79, Fax +41316329416 
tiate the diagnosis of sarcoidosis in about $80 \%$ of children. In the presented case the tests revealed equivocal results or were not reported. Tests supporting the diagnosis of CVID such as the production of antibodies upon challenge with antigen tetanus and diphtheria, the reduced proliferation of T cells with reduced IL2 and CD40 ligand expression were temporarily fulfilled [4]. Reduced CD4and increased CD8-positive T cells are seen in about 20$30 \%$ of patients with CVID and are not diagnostic for sarcoidosis or CVID either in blood or in BAL.
Despite extensive immunologic tests the conclusion from this case that a disturbed immune response forms the basis for sarcoidosis whether with or without infective or noninfective agents is speculative. To make the case even more complex, one could also speculate whether this case could be attributed to human interferon- $\gamma$-receptor- 1 deficiency with nontuberculous disseminated mycobacterial infections. This is nothing but another hypothesis $[5]$.

\section{References}

1 Sutor GC, Febel H: Sarcoidosis and common variable immunodeficiency. A case of malignant course of sarcoidosis in conjunction with severe impairment of the cellular and humoral immune system. Respiration 2000;67:204208.

2 Marcille R, McCarthy M, Barton JW, Merten DG, Spock A: Long-term outcome of pediatric sarcoidosis with emphasis on pulmonary status. Chest 1992;102:1444-1449.

3 Hermaszewski RA, Webster ADD: Primary hypogammaglobulinemia: A survey of clinical manifestations and complications. Q J Med 1993;86:31-42.
4 Farrington M, Grosmaire LS, Nanoyama S, Fischer SH, Hollen DD, Ledbetter JA, Noelle RJ, Arutto A, Ochs HD: CD40 ligand expression is defective in a subset of patients with common variable immunodeficiency. Proc Natl Acad Sci USA 1994;91:1099-1103.

5 Holland SM, Dorman SE, Kwon A, PithaRowe IF, Frucht DM, Gerstberger SM, Noel GJ, Vesterhus P, Brown MR, Fleisher TA: Abnormal regulation of interferon- $\gamma$, interleukin12 , and tumor necrosis factor- $\alpha$ in human interferon- $\gamma$-receptor-1-deficiency. J Infect Dis 1998;178:1095-1104. 